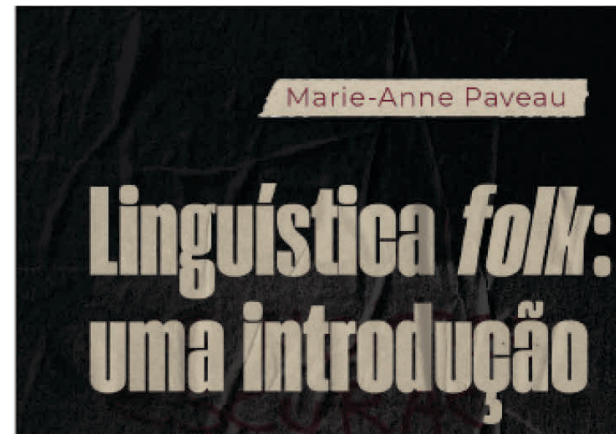

Letraria

Roberto Leiser Baronas Tamires Cristina Bonani Cont Julia Louterı̧̧o Custo

\title{
PROBLEMATIZANDO FRONTEIRAS: DISCUSSÕES INTRODUTÓRIAS DA LINGUÍSTICA FOLK, POPULAR, PROFANA, NÃO ERUDITA (E TRANSGRESSIVA)
}

PAVEAU, Marie-Anne. Linguística folk: uma introdução. Organizado por Roberto Leiser Baronas, Tamires Cristina Bonani Conti e Julia Lourenço Costa. Araraquara: Letraria, 2020.

Resenhado por: Bianca Franchini da Silva* Dandara Silveira Monteiro** Letícia Ferreira Camargo ${ }^{* * *}$

\footnotetext{
* Mestra e Doutoranda pelo Programa de Pós-Graduaça em Linguística (PPGL), da UFSC. Graduada (licenciatura e bacharelado) em Letras pela UFSC. É integrante do Grupo de Estudos do Campo Discursivo e do Laboratório Interdisciplinar de Ensino, Pesquisa e Extensão em sexualidades (AFrodite). E-mail: bifranchini@live.com.

** Mestra e Doutoranda pelo Programa de Pós-Graduação em Linguística (PPGL), da UFSC. Graduada (licenciatura) em Letras pela UFSC. É bolsista de Ações Afirmativas CAPES/PROPG e integrante do Grupo de Estudos do Campo Discursivo. E-mail: dandara.s.monteiro@gmail.com

*** Mestranda pelo Programa de Pós-Graduação em Linguística (PPGL), da UFSC. Bolsista da Fundação de Amparo à Pesquisa e Inovação do Estado de Santa Catarina (FAPESC). Bacharel em Linguística pela UNICAMP. É integrante do Grupode EstudosdoCampoDiscursivo. E-mail: letcletc@gmail.com.
} 
Organizado por Roberto Leiser Baronas, Tamires Cristina Bonani Conti, Julia Lourenço Costa - pesquisadores da Análise do Discurso da Universidade Federal de São Carlos (UFSCar) ${ }^{1}$-, o livro Linguística folk: uma introdução reúne nove diferentes textos de Marie-Anne Paveau, já publicados anteriormente em periódicos franceses. A referida obra é estruturada em duas partes, Definições e conceitos e Aplicações e perspectivas, convergindo com as intenções dos organizadores. De maneira não somente a problematizar e a, supostamente, introduzir (conforme título adotado) a relevância da linguística popular e dos estudos metadiscursivos para a linguística, os organizadores demonstraram ter em vista possibilitar a discussão epistemológica e social dos saberes folk para, inclusive, aplicá-los nos domínios das ciências da linguagem e nas práticas de ensino de língua. Conforme esses escritos e a resenha aqui elaborada, Marie-Anne Paveau (e as/os pesquisadoras/es ligados a essa obra) defendem o rompimento das fronteiras e dos dualismos, o que, adiante, associaremos à transdisciplinarização/transgressão dos estudos linguísticos contemporâneos.

Inicialmente, em A linguística "fora do templo", de modo a explorar a preocupação que paira nos diversos campos do conhecimento, que é a "[...] robusta interrogação sobre a natureza dos saberes" (PAVEAU, 2020, p. 13), Marie-Anne Paveau se propõe a discutir, por meio de três objetivos principais, como se dá a linguística popular no campo das ciências da linguagem. O primeiro desses objetivos centra-se na comparação entre a linguística popular (ou linguística folk - folk linguistics) bem estabelecida no domínio científico anglo-saxônico (sobretudo, norte-americano) e alemão (Volkslinguistik, às vezes chamada de Laienlinguistik) - fazendo parte da linguística geral - e a ausência/raridade (em suas palavras) desses estudos no domínio francês e francófono. Aliás, no final desse capítulo, ela acentua que, a partir do contato com os organizadores do livro aqui resenhado, a linguística folk também é obscura no Brasil. Além dessa questão que chamou de geografia da linguística popular, esse primeiro objetivo, é permeado por problematizações dos termos e das categorias folk e popular. Enquanto bem estabilizado nos estudos anglo-saxões, o termo popular, por exemplo, em francês (assim como em português), é polissêmico e carrega, ainda, as conotações pejorativas.

Quanto ao segundo dos objetivos, o desejo de Paveau é traçar, no domínio francófono - apesar da inexistência -, os objetos e os materiais de estudo desse campo, que poderiam ser qualificados como "práticas linguísticas profanas" (PAVEAU, 2020, p. 13, grifos da autora). Assim dizendo, em comparação com as normatividades linguísticas e gramaticais, chamadas de purismos, as práticas profanas estariam ordenadas, por assim dizer, em quatro práticas linguísticas: a descritiva (em que a atividade da linguagem é descrita), a normativa (em que os comportamentos da linguagem são prescritos), a intervencionista (em que pesquisadores/as intervêm sobre os usos da linguagem) e a militante (em que são problematizados os usos linguísticos que são machistas, racistas, homofóbicos, entre outros preconceituosos).

O terceiro objetivo do capítulo, por fim, é defender (iniciar uma reflexão sobre) a validade e a legitimidade dos saberes profanos como parte do domínio da linguística, não se limitando à teoria, mas se estendendo às práticas de ensino-aprendizagem de línguas. Para isso, é preciso que as fronteiras disciplinares, segundo Paveau, saiam da oposição binária entre linguistas - autorizados a dizer sobre a língua - e não-linguistas (purismo versus profanação), pois esta seria uma fragilidade proveniente dos idealismos e dos objetivismos do modelo científico das ciências exatas. A autora explora, então, alguns levantamentos de natureza epistemológica, teórica, prática e representacional para o tratamento dos estudos da linguagem mais dinâmicos.

Mais uma das interrogações propostas por Paveau (2020) é a que intitula o segundo capítulo: Não-linguistas fazem linguística? Aproveitamos e complementamos tal título com as próprias palavras da autora, em constante questionamento: "[...] como [se] identifica essa categoria de falantes que produzem enunciados avaliativos sobre a própria língua e a língua dos outros, metalinguísticos e metadiscursivos a partir de posições subjetivas não disciplinares e não acadêmicas?” (PAVEAU, 2020, p. 28). A pesquisadora francesa afirma que a identidade/identificação dos não-linguistas é uma tarefa difícil no âmbito da linguística folk. Prezando a adoção de uma "visão escalar das coisas" (PAVEAU, 2020, p. 28), que não se reduza aos polos limitantes do idealismo, a autora diz compartilhar da visão de Günter Schmale (2008) de que a linguística popular seria o lugar em que se cruzam a linguística científica, a linguística amadora e aquela com pretensões didáticas e de divulgação. Propõe, então, uma tipologia dos não-linguistas que (i) não se encerra a um estado permanente, mas que têm uma atividade praticável (inclusive por linguistas) em momentos e

${ }^{1}$ Os textos de Marie-Anne Paveau reunidos nesse livro foram traduzidos pelas pessoas especialistas em linguística: Érika de Moraes, Fernando Curtti Gibin, Marco Antonio Almeida Ruiz, Maria de Fátima Sopas Rocha, Mariana Luz Pessoa de Barros, Mônica Magalhães Cavalcante, Paula Camila Mesti, Phellipe Marcel da Silva Esteves e Samuel Ponsoni. 
lugares definidos e que (ii) guarda uma posição de não-linguistas, que é mutável. Como exemplo, cita as atividades de escritores, de juristas, de logófilos, de ludolinguistas e de militantes. Adiante, mais uma questão é posta em jogo pela autora: de que valem as teorias folk? Para respondê-la, diz haver três possibilidades: primeira, a eliminativa, do filósofo Paul Churchland; segunda, a intermediária, do também filósofo Daniel Dennet; e, terceira, a integracionista. Esta última, defendida pela autora, tem como chave a noção de epilinguístico, cara aos estudos de Linguística Aplicada (LA) no Brasil. As dimensões experiencial e cultural da linguagem, de ordem prática e representacional, que são dados da linguística folk, precisam provocar - conforme defende a francesa - a desestabilização dos saberes linguísticos (tidos como saberes científicos "duros"). Ou seja, o objeto da linguística precisa ser repensado, a partir de um lugar antieliminativo.

No terceiro capítulo - As normas perceptivas da linguística popular -, publicado originalmente em 2007, a analista discorre (novamente) sobre a estabilização da linguística folk enquanto campo de estudos nos Estados Unidos e na Alemanha. Em comparação, diz que os estudos de linguística folk na França existem, mas que são tratados de acordo com outras orientações. Dito isso, Paveau (2020, p. 47) faz seu questionamento (entendido como provocativo): "[...] se a linguística popular não existe como campo científico na França, mas ela produz um conhecimento presente e disponível aos pesquisadores, então onde ela se situa?”. Sem ainda citar a prática linguística militante, somente as outras três (descritiva, normativa e intervencionista), ela defende o deslocamento que sai dos binarismos entre descritivo versus prescritivo, entre ciência versus popular, e se direciona para a percepção. Esta seria o entrelaçamento de ambos objetos examinados, somados ao coeficiente de informação social e cultural dos conhecimentos produzidos, os quais, segundo a autora (PAVEAU, 2020, p. 54), "[...] são justificáveis para um estudo específico em linguística, não como uma cartilha ingênua sobre a qual fundar a ciência, mas como uma possível versão da teoria da linguagem: Daninos e Labov, Proust e Weinreich”.

Em O falar das classes dominantes: linguística popular e dialetologia perceptiva, texto que conclui a primeira parte do livro, Paveau faz um panorama contrastante entre a frequência de manifestações: científicas e espontâneas, do falar das classes dominantes e do falar popular. O falar das classes dominantes pouco figura como objeto de investigações científicas de linguística folk, mas é estigmatizado no humor, na literatura e no cinema, por exemplo. Inversamente, o falar popular é objeto majoritário das linguísticas científicas e pouco presente nas metalinguagens espontâneas. O falar das classes dominantes é igualmente permeado por marcas específicas e não representa a norma culta da língua, como é considerado em alguns espaços da linguística profissional. A autora apresenta alguns dos aspectos desse socioleto das classes dominantes, percorrendo desde a pronúncia e a entonação até o léxico, o nível da língua e as interações conversacionais, argumentando que esse falar constrói apoios identitários da classe, o que não ocorre com o falar popular. Discutindo o problema da validade científica da linguística folk, Paveau reafirma a legitimidade do corpus folk, que, inclusive, contribui para a sustentação de sua posição integracionista. Uma de duas posturas epistemológicas derivadas de Labov (1966), a integracionista, sugere haver pouco distanciamento entre as análises de linguistas e de não-linguistas e propõe os saberes dos nãolinguistas como sendo legítimos. A eliminativista, por sua vez, reconhece linguística folk como teoria, mas rejeita como falsa.

A segunda parte do livro, Aplicações e perspectivas, é iniciada com o capítulo, também questionador, Linguística popular e ensino de língua: categorias em comum?. Nesse texto, a primeira tarefa a que Paveau se propõe é definir o que é "linguística popular": o saber espontâneo, diferente do científico acadêmico. A autora retoma que a ausência de desenvolvimento da linguística popular na França estaria pautada pela relação de veneração de saberes "seguros" e pelo desprezo de saberes aproximados, estando esse campo vinculado a estes segundos e considerado parte da sociolinguística. Paveau (2020) reafirma sua defesa de que a linguística popular deve constituir um campo próprio e não ser restrita à atuação da sociolinguística, sendo necessário englobar, também, as práticas de ensino-aprendizagem. Nesse cenário, as manifestações linguísticas espontâneas das/des/dos alunas/es/os², caracterizadas entre descritivas, normativas e intervencionistas, não devem ser descartadas por docentes, desde que preparadas/os em sua formação, mas aproveitadas enquanto oportunidade para promover reflexões de ensino, como, por exemplo, sobre regra e memória (SAVELLI et al. 2002 apud PAVEAU, 2020), visto que “[...] os falantes racionalizam sua língua, a arrumam e a organizam, como um ambiente onde a ordem e a harmonia são necessárias" (PAVEAU, 2020, p. 77).

\footnotetext{
${ }^{2}$ Adotamos o uso da distinção de gênero aqui, como forma de militar essa temática emergente nas práticas linguísticas atuais, apesar de não estar marcada nesses textos de Paveau.
} 
Na sequência, A língua sem classes da gramática escolar aborda a relação entre a representação unitária da língua francesa e seu papel fundamental no ensino (e na sociedade) e o silenciamento da existência da variação na língua nas práticas escolares, particularmente a variação social. Antes que se faça a problematização proposta, Paveau (2020, p. 85) não deixa dúvidas: "[...] por razões práticas e também didáticas, sociais e até ideológicas, é realmente o francês padrão que deve ser ensinado na escola”. Não obstante, a autora aponta que a imposição da norma padrão enquanto única possível nas gramáticas escolares empobrece o repertório social das/des/dos estudantes e não se relaciona às práticas sociais, ignora gírias, oralidade e dinâmicas de poder. Retomando exemplos da estratificação social da língua, argumenta que a linguística popular tem refletido sobre a importância da dimensão social da língua e sua integração ao ensino; entretanto, afirma que, na própria sociolinguística, ocorre a "desclassificação" da língua com o termo técnico linguística diastrática. Ao defender a integração da dimensão social da língua ao ensino, Paveau (2020, p. 95), novamente, afirma que "[...] como sempre, apenas uma formação sólida de professores, incorporando um discurso reflexivo sobre sua própria variedade, sem negação ou desprezo, permite manter uma posição cientificamente rigorosa e pedagogicamente eficaz”.

Em Imagens da língua nos discursos escolares, Paveau (2020) questiona os entendimentos a respeito do discurso escolar e as suas relações com realidades externas ao contexto educacional. Nesse sentido, a autora pontua o fato de os discursos escolares serem limitados ao que se produz dentro da escola, desconsiderando, de forma mais ampla, outros elementos que envolvam e que atravessem os discursos das/des/dos estudantes, como o contexto familiar e as demais relações sociais. Assim, mostra-nos que os discursos escolares precisam considerar a polifonia - termo bakhtiniano que associa a linguagem às situações de interação. Assim, para abordar as conexões internas e externas dos discursos escolares, a autora reflete sobre as variadas concepções de língua adotadas nessa esfera, destacando quatro imagens da língua dominantes: a língua-mundo (a vida espelhada por meio da língua), a línguanorma (as regras de uso), a língua invariável (o ensino de formas limitadas de uso) e a língua-silêncio (a limitação da conversação e da aprendizagem em sala de aula). Dessa forma, Paveau (2020, p. 98) salienta que as quatro imagens se complementam para legitimar o propósito de “[...] dizer a verdade das coisas aos alunos", a partir de determinados padrões.

No capítulo seguinte, As vozes do senso comum nos discursos sobre a escola, a autora debate a respeito do senso comum e de suas relações com os discursos escolares. Desse modo, ao refletir sobre senso comum - segundo ela, conceito central em análise dos discursos -, Paveau apresenta duas dimensões: a semântica (ou paradigma linguageiro) e a perceptivo-cognitiva. A primeira diz respeito à "[...] coconstrução do sentido em discurso, fundada num acordo silencioso, cujo funcionamento procuramos entender, a partir da articulação da linguagem e da pré-linguagem" (PAVEAU, 2020, p. 107); já a segunda refere-se às redes de crenças e de saberes "[...] que configuram e prefiguram a experiência humana, e que informam profundamente os discursos dos locutores" (PAVEAU, 2020, p. 107). Para essa análise do senso comum, a autora apresenta uma seleção de ensaios sobre o retorno das aulas em 1999, os quais tiveram grande repercussão midiática, numa materialização do senso comum sobre os discursos escolares - que procurava, então, manter os padrões educacionais e de construção da língua. Assim, Paveau demonstra que o senso comum opera tanto no individual quanto no coletivo, na medida em que a construção do discurso por cada sujeito envolve os saberes coletivos prévios e, ainda, a apropriação e a circulação desse discurso construído individualmente. A francesa se propõe a analisar como o senso comum se manifesta no discurso a partir de três níveis: (i) o pré-discursivo (que são conhecimentos prévios compartilhados por comunidades discursivas); (ii) o metadiscursivo (que envolve os comentários dos sujeitos a respeito de seus discursos e as relações com o senso comum); e (iii) o discursivo (que é construído por meio de certas composições cognitivo-textuais e enunciativas).

No último capítulo do livro, A linguística fora de si mesma: em direção a uma pós-linguística, Paveau defende (conforme outros textos/capítulos) que a linguística popular está associada aos sujeitos que falam, sobre o que falam e o que os outros comentam sobre essa fala (PAVEAU, 2020, p. 128), sem a necessidade de conhecimento científico para tal, portanto, abandonando o estatuto de nãolinguistas. Assim, a francesa propõe uma provincialização da linguística, que consiste no rompimento das fronteiras e dos dualismos, em um movimento de considerar e de dar passagem às experiências e aos discursos dos variados sujeitos. De acordo com ela, a provincialização seria um deslocamento do centro que passe a considerar as margens. Nesses deslocamentos, pensando na pluralidade dos discursos, Paveau trata da ecologia e de suas relações com a materialidade discursiva. Assim, a autora propõe uma análise do discurso digital, ou tecnodiscurso, por considerar a web determinante para a prática pós-linguística, por ser o ambiente em que especialistas e não especialistas encontram espaços de fala. 
A cada capítulo, Linguística folk: uma introdução convida quem lê a adentrar novas nuances da linguística folk e expandir as fronteiras do campo proposto, ainda em estágio embrionário no Brasil, mas repleto de possibilidades. Acreditamos que incursões à área têm muito a oferecer aos estudos linguísticos no país, e incentivamos a audiência de linguistas e não-linguistas a explorarem os espaços em aberto.

A iniciativa dos organizadores - reunidos a partir da figura do professor Baronas e de sua trajetória multifacetada nos estudos discursivos -, de unir escritos de Marie-Anne Paveau, demonstra precisão e acuidade e se torna base profícua para alinhavar/incentivar pesquisas/diálogos que permeiam a linguística popular, principalmente por despertar reflexões a respeito dos estudos da linguagem e dos campos discursivos, em um repensar das práticas. A costura que propusemos, de resumir capítulo a capítulo, acompanhou a estrutura da própria obra e, agora, ao final, nós nos permitimos pensar nas inquietações com as quais trabalhamos nos estudos do campo discursivo. As discussões/(des)catergorizações/aspirações da linguística popular nos parecem ser caras à Linguística Aplicada (LA) Contemporânea, com a qual convergimos/estudamos/defendemos, que, no "[...] exercício de constantemente atravessar fronteiras" (MOITA LOPES, 2006, p. 26), é transdisciplinar, por não se privar a apenas uma disciplina e por considerar a criação de inteligibilidades sobre a rede de práticas, de discursos, de dispositivos contemporâneos com base nas (e com as) vozes que se encontram às margens. Nessa esteira, que vislumbra a práxis em movimento e encarrega-se de uma abordagem mutável para questões da linguagem em relações múltiplas, a LA é, também, "transgressiva" (PENNYCOOK, 2006), por investigar/aprofundar urgências linguísticas, cujas inquietações são atravessadas e deslocadas por práticas anti-hegemônicas e interseccionais, ao envolver os corpos, a raça, o gênero, a sexualidade e os variados discursos de recusa dos padrões vigentes de exclusão, ou seja, práticas linguísticas militantes (PAVEAU, 2020).

Por todas essas importantes questões que coloca e por uma série de outras que aqui não podemos esgotar e pela importância de trazer o debate sobre a linguística popular para o Brasil - assim como já foi feito em edições de periódicos como a Porto de Letras (v.7, n.4, 2021) e esta Fórum Linguístico (v. 16, n. 4, 2019), o livro organizado por Baronas, Bonani e Costa é leitura obrigatória para aqueles e aquelas que prezam os vértices que a linguagem oferece e que a pesquisa em linguagem exige.

\section{REFERÊNCIAS}

MOITA LOPES, L. P. Uma linguística aplicada mestiça e ideológica: interrogando o campo como linguista aplicado. In: MOITA LOPES, L. P (org.). Por uma linguística aplicada indisciplinar. São Paulo: Parábola, 2006. p. 13-44.

PENNYCOOK, A. Uma linguística aplicada transgressiva. In: MOITA LOPES, L. P (org.). Por uma linguística aplicada indisciplinar. São Paulo: Parábola, 2006. p. 67-84.

\section{(1) $\circledast$}

Recebida em 19/02/2021. Aceita em 21/03/2021. 